\title{
Burden of Malaria in Children Presenting with Anaemia at Ola During's Children's Hospital in Freetown Sierra Leone
}

\author{
Yaguo Ide Lucy Eberechukwu ${ }^{1}$, Lannes Namusa Susan Kamara ${ }^{2}$ \\ ${ }^{1}$ Department of Paediatrics and Child Health, University of Port Harcourt Teaching Hospital, Port Harcourt, Nigeria \\ ${ }^{2}$ Department of Paediatrics, College of Medicine and Allied Health Sciences, University of Sierra Leone, Freetown, Sierra Leone
}

\section{Email address:}

lucyaguolucy@gmail.com (Y. I. L. Eberechukwu)

\section{To cite this article:}

Yaguo Ide Lucy Eberechukwu, Lannes Namusa Susan Kamara. Burden of Malaria in Children Presenting with Anaemia At Ola During's Children's Hospital in Freetown Sierra Leone. American Journal of Pediatrics. Vol. 5, No. 2, 2019, pp. 70-73.

doi: 10.11648/j.ajp.20190502.16

Received: March 11, 2019; Accepted: May 20, 2019; Published: June 13, 2019

\begin{abstract}
Malaria is a serious public health problem in sub-Saharan Africa, where it affects entire populations especially children. Indeed over $80 \%$ of the worldwide cases of malaria occur in Africa. Anemia secondary to malaria is much more common in younger children, with high mortality rates. Malaria is endemic throughout Sierra Leone and it is often associated with haemoglobin level below 8.0 grams per decilitre in malaria-endemic regions such as Sierra Leone. Sixteen percent of children age 6-59 months in Sierra Leone had a haemoglobin count lower than $8.0 \mathrm{~g} / \mathrm{dl}$. The aim of this study was to describe the burden of malaria in children aged one to five years presenting with Anaemia at Ola During children's Hospital (ODCH) in Freetown Sierra Leone. This study was a hospital-based descriptive cross-sectional study, carried out over a period of two months. Data obtained from the study was analyzed using descriptive statistics, where discrete variables were summarized using frequencies and percentages; continuous variables were summarized using measures of central tendency such as mean, median, mode and standard deviation; while measures of association were analyzed using chi square. Eighty-eight percent of the children in this study had anaemia, mean hemoglobin concentration of enrolled children was $6.9 \mathrm{~g} / \mathrm{dl}$ Fifty-seven-point two percent of the study population had positive blood slide for malaria and the only plasmodium specie detected was plasmodium falciparum. Only 53\% of the study population slept under insecticide treated bed nets Parents and caregivers with no formal education were as much as $11.8 \%$. A little over a quarter of the parents/caregivers earned less than 200,000leones which is equivalent to $<50$ USD.
\end{abstract}

Keywords: Malaria, Children, Anaemia Burden

\section{Introduction}

Malaria is a serious public health problem in sub-Saharan Africa, where it affects entire populations especially children. Indeed over $80 \%$ of the worldwide cases of malaria occur in Africa. Anemia secondary to malaria is much more common in younger children, with high mortality rates. [1-3] Malaria is endemic throughout Sierra Leone, and the most predominant plasmodium species in Sierra Leone is p. falciparum. According to the SLDHS 2013. [3] Pathogenesis of severe anemia in malaria include- increased sequestration of parasitized erythrocytes, destruction of both parasitized and non-parasitized red blood cells, splenic phagocytosis of infected red cells, immune-mediated destruction of erythrocytes, dyserythropoiesis, and ineffective erythropoiesis within the bone marrow, and lower erythroblast proliferative rates and numbers. [4] The relative contributions of the aforementioned mechanisms differ according to the patients' age, anti-malarial immune status, genetic constitution, and the local endemicity of malaria. Hemolysis is of greater importance in causing anemia in nonimmune children with acute malaria, whereas dyserythropoiesis plays a major role in causing anemia in children with recurrent or frequent falciparum malaria. However, it is thought that several mechanisms are likely to operate in any one individual. [4. 5] There is a dearth of studies on malaria in children aged one to five years with Anaemia in Freetown, hence the need for this study. 


\section{Materials and Experiments}

\subsection{Study Area: Ola During Children's Hospital Sierra Leone}

Sierra Leone is located along the west coast of Africa. The study was conducted at the Ola During Children's Hospital $(\mathrm{ODCH})$ in Freetown, the capital city of Sierra Leone. $\mathrm{ODCH}$ is a 300 bed capacity specialized children's hospital, which provide both in-patient and out-patient services.

\subsection{Study Population}

Children aged 1-5 years, presenting with anaemia at the Ola During Children's Hospital.

\subsection{Selection and Enrolment of Patients}

\subsubsection{Inclusion Criteria}

i. All children aged 1-5 years with $\mathrm{Hb}$ level less than 9.0 $\mathrm{g} / \mathrm{dl}$, presenting at the Ola During Children's Hospital. (According to the WHO definition of anemia, children aged less than 6 years are anemic if their $\mathrm{Hb}<9.3 \mathrm{~g} / \mathrm{dl}$. For ease of analysis in this study, children with $\mathrm{Hb}<9.0$ $\mathrm{g} / \mathrm{dl}$ were considered anemic).

ii. Children whose parent or care-giver was willing to give written consent.

\subsubsection{Exclusion Criteria}

Children whose parent or guardian decline to give consent.

\subsubsection{Sampling Method}

Consecutive sampling method was used. This is a nonprobability sampling technique, where every next patient who presented to ODCH within the study period and meets the inclusion criteria was enrolled and recruited into the study, until the calculated sample size was reached.

\subsubsection{Sample Size Determination}

The sample size was determined using Fisher's formula for sample size determination:

$$
\mathrm{n}=\frac{\mathrm{z} 2 \mathrm{p}(1-\mathrm{p})}{\mathrm{d} 2}
$$

$\mathrm{n}=$ sample size

$\mathrm{z}=$ confidence interval $(95 \%)=1.96$

$p=22.1 \%=0.221$ (proportion of children aged less than 5 years, with helminth and malaria co-infection, estimated as per Francis Zeukeng et al study in Cameroon [5]).

$\mathrm{d}=$ study precision (taken as $5 \%=0.05$ ).

$$
\mathrm{n}=\frac{1.962 \times 0.221 \times(1-0.221)}{0.052}=264
$$

\subsection{Data Collection, Management and Analysis}

\subsubsection{Study Procedure}

The study was conducted over a two-month period $1^{\text {st }}$ of September to $31^{\text {st }}$ of October.

\subsubsection{Determination of $\mathrm{Hb}$ Level}

$1 \mathrm{ml}$ of whole blood was taken from a superficial vein into a tube containing ethylene diamine tetra acetic acid (EDTA). It was stored at room temperature and taken to the laboratory within 6 hours of collection, to be analyzed for full blood count parameters including- $\mathrm{Hb}$, Hct, MCV, and MCHC- by standard Coulter gram.

\subsubsection{Determination of Malaria Parasites}

The finger tip of the patient was cleaned with surgical spirit and cotton wool, and pierced with a sterile lancet. The first drop of blood obtained was wiped from the fingertip using clean dry cotton wool. Then 2-3 drops of blood were used to prepare a blood smear by spreading the drops of blood on the blood slide with another plain blood slide. The blood slides were then left to air-dry and then taken to the laboratory the same day for analysis by use of Giemsa stain and microscopy.

\subsection{Data Management and Analysis}

Data was collected using a structured questionnaire, and entered into a password protected Microsoft Access database. The hard copy data forms were stored so that at the completion of data entry, comparisons can be made between the soft and hard data copies in order to identify any errors.

Data obtained from the study was analyzed using descriptive statistics-

i. Discrete variables were analyzed using frequencies and percentages.

ii. Continuous variables were analyzed using measures of central tendency such as mean, median, mode, and standard deviation.

Data is presented in the form of tables, graphs, and narratives.

\section{Results}

About 300 children aged one to five years were screened, of which 264 children who met the inclusion criteria $(\mathrm{Hb}<$ $9 \mathrm{~g} / \mathrm{dl}$ ), together with their consenting parents/ caregivers were enrolled into the study. The mean age of children aged one to five years, enrolled into the study was 2.6 years (SD 2.2). The majority113 (42.8\%) were aged between one to less than two years old. The majority of the study subjects were males158 (59.8\%), whilst $106(40.2 \%)$ were females. M: F ratio of 1.49: 1 .

Table 1. Demographic characteristics of Patients

\begin{tabular}{ll}
\hline Variable & Frequency $(\%)$ \\
\hline Mean age in years (SD) & $2.6(2.2)$ \\
1 to $<2$ years old & $113(42.8)$ \\
2 to $<3$ years old & $64(24.2)$ \\
3 to $<4$ years old & $44(16.7)$ \\
4 to 5 years old & $43(16.3)$ \\
Sex & \\
Male & $158(59.8)$ \\
Female & $106(40.2)$ \\
\hline
\end{tabular}


Table 2. Full Blood Count.

\begin{tabular}{ll}
\hline Full blood Count & Mean (Standard Deviation) \\
\hline Hb concentration & $6.9(1.6)$ \\
$\mathrm{Hct}$ & $21.0(5.1)$ \\
$\mathrm{MCV}$ & $77.3(19.9)$ \\
$\mathrm{MCHC}$ & $33.0(0.6)$ \\
\hline
\end{tabular}

The above values show a microcytic hypochromic anemia. PREVALENCE OF MALARIA.

One hundred and fifty-one (57.2\%) of the patients had a positive blood slide for malaria parasites, and showed plasmodium falciparum as the only plasmodium specie while $113(42.8 \%)$ had a negative blood slide for malaria.

Table 3 PREVALENCE OF MALARIA.

\begin{tabular}{ll}
\hline Variable & Frequency (\%) \\
\hline Blood slides for malaria parasites & \\
Plasmodium species & \\
Positive: P Falciparum & $151(57.2)$ \\
Negative & $113(42.8)$ \\
\hline
\end{tabular}

\section{SOCIO-ECONOMIC CHARACTERISTICS:}

Table 4. Socio-economic characteristics $(n=264)$.

\begin{tabular}{ll}
\hline Variable & Frequency (\%) \\
\hline Caregiver's age, mean (SD) & $28.8(9.7)$ \\
Caregivers education level & \\
No formal education & $31(11.8 \%)$ \\
$<$ JSS1 (< form 1) & $88(33.3 \%)$ \\
JSS1-JSS3 (form 1 - 3) & $40(15.2)$ \\
SSS1-SSS3 (form 4-6) & $69(26.1)$ \\
$>$ SSS3 (college/ university) & $36(13.6)$ \\
Care givers average monthly household income in SLL & \\
$<200,000(<50$ USD) & $73(27.7)$ \\
200,000-400,000 (50-100 USD) & $80(30.3)$ \\
$>400,000$ (> 100 USD) & $53(20.1)$ \\
Unemployed & $58(22.0)$ \\
Number of people per household & $6.3(3.1)$ \\
Does patient sleep under ITN & \\
Yes & $140(53.0)$ \\
No & $124(47.0)$ \\
Type of toilet facility & \\
Flush toilet & $83(31.4)$ \\
Pit latrine & $176(66.7)$ \\
Others & $5(1.9)$ \\
\hline
\end{tabular}

\section{Discussion}

This study found a high prevalence of malaria of $57.2 \%$, Plasmodium falciparum, being the predominant malaria parasite found in this study, and is reported to be predominant in Sierra Leone. [3] and Cameroon as reported by Francis Zeukeng et al in Cameroon in 2014. [5] Price et al working in Thailand, reported age less than five years and pure plasmodium falciparum infection rather than mixed plasmodium infections as risk factors for developing anemia following plasmodium falciparum infection. [6] This might very well be the reason for the finding in this study. There was a general male preponderance $(59.8 \%)$, which is in contrast with the study of Kining'hi et al in Tanzania that reported a female preponderance. [7] This is in contrast to a slightly higher female to male ratio of 1.08: 1 of Sierra
Leonean children aged one to five years according to the Sierra Leone Demographic and Health survey. [3] Male children are valued more than female children in Sierra Leone This might also explain why more sick male children would be brought into hospital more than the female children.

Mean age of children enrolled into study was 2.6 years, with a mean $\mathrm{Hb}$ of $6.9 \mathrm{~g} / \mathrm{dl}$ comparable to the work of Lyke et al in Mali in 2004 where a mean age of anaemic children of 3 years with a mean $\mathrm{Hb}$ of $6.12 \mathrm{~g} / \mathrm{dl}$. [8] was reported. Majority of the anaemic children were between one to two years comparable to the work of Smithson et al in Tanzania. [9] This age group appears to be more susceptible to anemia. Less than half of the children did not sleep under insecticide treated bed net this is comparable to the work of Nalley et al working in Nigeria, where ITN use was 34.6. [10] The insecticide treated bed net is meant to provide personal protection from malaria and subsequently from its complications such as anaemia. [11] $11.6 \%$ of the parents/caregivers in this study had no formal education which is lower than $2 \%$ reported by Nalley et al in Nigeria. [10] This can be explained by the fact that educational standards are higher in Nigeria than Sierra Leone. [12]

\section{Conclusion}

Malaria prevalence is high among children aged one to five years who present with anaemia in Freetown Sierra Leone. There is a high number of parents or caregivers with no formal education. The number of children not sleeping under insecticide treated bed nets is also high. It is therefore recommended that there should be increased awareness of the use of insecticide treated bed nets. Attention should also be paid to education, to improve literacy.

\section{References}

[1] Policarpo Ncogo, Maria Romay, Agustin Benito, Pilar Aparicio, Gloria Nseng, Pedro Berzosa, Maria A. SantanaMorales, Matilde Riloha, Basilio Valladares, Zaida Herrador Prevalence of Malaria and associated factors in children living in urban and rural settings from Bata districts, Equitorial Guinea, PLoS One. 2017; 12 (5): e0176613.

[2] World Health Organization (WHO). World malaria report 2017www.who.int/malaria.

[3] Sierra Leone Demographic and Health Survey 2013: 12.

[4] Nicolas J White Anaemia and Malaria Malaria Journal 2018; 17: 371 .

[5] Zeukeng F, Tchinda VH, Bjgoga JD, et al. co-infections of malaria and geo-helminthiasis in two rural communities in Cameroon; PLoS Negl Trop Dis 2014 oct; 16; 8 (10): e3236.

[6] Price RN, Simpson JA, Nosten F, et al. Factors contributing to anaemia after uncomplicated falciparum malaria. Am. J. Trop. Med. Hyg. 2001; 65: 614-622. 
[7] Kining'hi SM, Magnussen P, Kaatano GM, et al. Malaria and helminth co-infections in school and preschool children. PLoS One, 2014 Jan 29; 9 (1): e86510.

[8] Lyke KE, Burges R, Cissoko Y, et al. Serum levels of the proinflammatory cytokines interleukin-1 beta (IL-1 beta), IL-6, IL-8, IL-10, tumor necrosis factor alpha, and IL-12 (p70) in Malian children with severe Plasmodium falciparum malaria and matched uncomplicated malaria or healthy controls. Infect. Immun. 2004; 72: 5630-5637.

[9] Smithson P, Florey L, Salgado S, et al. Impact of malaria control on mortality and anemia among Tanzanian children less than five years of age, 1999-2010; PLOS One, 2015; 10 (11): e0141112.
[10] Nalley Joy Chinwe, George Innocent Ocheyana, Opara Peace Ibo, Yaguo-Ide Lucy Eberechukwu The Use of Insecticide Treated Bed Net in Children Under Five Years of Age in Alakahia Community, Rivers State American Journal of Pediatrics 2017; 3 (5): 32-41.).

[11] Vanden J, Thwing J, Wolkon A, Kulkarni AM, Manga A, Erskine M, et al. Assessing bed net use and non- use after long lasting insecticide net distribution: a simple framework to guide programmatic strategies. Malar J 2010; 9: 133-42.

[12] https://knoea.com/atlas/SierraLeone/topics/Education/Literacy/Adult-literacy-rate. 